\title{
Sounding the Arctic in Chantal Bilodeau's Climate Change Plays
}

\section{NASSIM W. BALESTRINI}

\begin{abstract}
Quebec-born playwright Chantal Bilodeau has been responding to the challenges of dramatizing anthropogenic climate change by developing an eight-part Arctic Cycle, each play of which is set in one of the nations that claims Arctic territory. Sila (2014) immerses audiences into a complex network of humans, animals, and mythical beings crisscrossing the Canadian Arctic. These movements circle around the Inuit concept of sila, which is the life-giving force of breath and voice. Thus, the sonic world of Sila focuses on voices speaking words, on performance poetry, and on the sounds of breath and wind. Bilodeau's second Arctic Cycle play, Forward (2016), addresses the long-term impact of Fridtjof Nansen's polar exploration of the 1890s on Norway's economy and society. In terms of sound, Forward features multiple musical performances ranging from traditional songs to European opera arias and Lieder to contemporary Norwegian electro-pop. The sonic features of both plays stress interdependence across time, space, as well as (non-)human, earthly, and metaphysical realms. Sila and Forward address climate change in a non-universalizing manner which promotes a heterarchical (rather than hierarchical) aesthetic fit for a growing awareness of planetary relationality.
\end{abstract}

\section{KEYWORDS}

climate change, soundscape, sonic cultures, Arctic, Inuit, Canada, Norway, interdependence, relationality, theory and practice 


\title{
Sounding the Arctic in Chantal Bilodeau's Climate Change Plays
}

\author{
Introduction: The Arctic Cycle
}

Chantal Bilodeau, a playwright originally from Quebec but now based in the New York metropolitan area, founded The Arctic Cycle a decade ago and is the initiative's artistic director. Having teamed up with artistic producer Julia Levine, artistic associate Thomas Peterson, and resident director Jennifer Vellenga, Bilodeau's central aim is to create eight full-length plays set in the eight nations that lay claim to Arctic territory. ${ }^{1}$ The first two plays indicate that Bilodeau conceptualizes each work simultaneously as an independent drama complete in itself and as a puzzle piece within the cycle. The first two dramas - which I will discuss based on the published texts rather than on specific productions $^{2}$ - encourage audiences to rethink climate-related phenomena through focusing, respectively, on space and time on a scale that they may not yet have considered. ${ }^{3}$ This essay hopes to show two main points: first, that strategic uses of sound may be one of the emerging patterns of the Arctic Cycle as a series of full-length plays and, second, that Bilodeau's approach to using sound contributes to an anti-hierarchical theatre aesthetics which strives not to replicate structures of domination.

Sila is set in the Canadian Arctic and juxtaposes, in its intertwined plots, different experiences of loss and mourning that, in some cases, open up lines of communication which produce glimpses of hope. Veronica, an Inuit mother who loses her teenage son to suicide in a community ravaged by alcoholism and unemployment, ultimately connects with Jean, a white scientist who only

1 Bilodeau is also known for her work with Climate Change Theatre Action (cofounded with Elaine Ávila, Roberta Levitow, and Caridad Svich; see <http://www.climatechangetheatreaction. $\mathrm{com} />$ ) and for her work as a curator at the online theatre forum at HowlRound.com (see <https:// howlround.com/>).

2 For information on productions, please consult $<$ http://thearcticcycle.org $>$. I would like to thank Chantal Bilodeau for providing lead sheets of the contemporary songs used in Forward.

3 The third play, No More Harveys, will premiere in September 2021, but the manuscript is not yet available (see "Balestrini 2020, 39-40). On space in Sila and time in Forward, see Balestrini 2017b, 2019a, and 2019b. 
realizes his myopic perspective on Inuit culture when he nearly drowns. Flanked by her mother, Leanna, a well-known climate change activist, and by Tulugaq, an Inuit elder with a crystal-clear grasp of Inuit and white Canadian cultures, both Veronica and Jean embrace the Inuit concept of sila - which is the animating power of all life forms - as a boundary-crossing link. In the play as a whole, sila connects variegated humans to the animal and the metaphysical realms in order to represent climate change as a planetary and cross-species condition. ${ }^{4}$ The central motif of breath-like sila fits into the play's focus on the speaking voice as its most prevalent sonic medium. Beyond words spoken in various contexts (dialogue with other characters, teaching, giving a speech), the play features an artistic variant, i.e., spoken-word poetry. Complementing the discussion of breath, voice, and conscious listening in the play, nonverbal sounds - such as the wind, the cracking of Arctic ice, animal sounds, cries for help, and (much less prevalently) technology-based sounds produced by a snow mobile and a gun - evoke sonic repertoires besides verbal self-expression.

The time frame of the second play, Forward, extends from the 1890s to the present. The central theme is the impact of Fridtjof Nansen's polar expedition on his family and on long-term economic development, especially of the Norwegian oil industry. Nansen's obsession with Arctic exploration at the expense of his family and of crew members is brilliantly depicted by placing him on the stage with a female embodiment of "ICE" as the 'object' of his desire. In addition to the explorer's personal and professional passions, the play offers glimpses into social changes triggered by the discovery of crude oil in Norwegian waters: the dislocation of some populations from the coast to urban areas, the loss of traditional coastal occupations, the rise in the level of education, and the fossil fuel-driven impact of climate change on landscapes and people in Norway. ${ }^{5}$ The broad time frame of Forward is complemented by the choice of music, which includes traditional seafarer songs sung in the late eighteen hundreds, nineteenth-century European opera and art songs, and contemporary Norwegian electro-pop.

These brief summaries already indicate that Sila and Forward feature a broad variety of sonic features that the playwright has woven into the social structures and the central conflicts of the plays. As the sound studies scholar Jonathan Sterne has argued: "By analyzing both sonic practices and the discourses and institutions that describe them, [sound studies] redescribes what sound does in the human world, and what humans do in the sonic world". ${ }^{6}$ Sterne's insistence on "sonic-spatial practices"7 applies poignantly to studying sound in the theatre because it highlights the experience of sound production and reception. ${ }^{8}$

Bilodeau employs sound to underline her overall method of communicating

4 For a detailed discussion of Sila and mobility, see Balestrini 2017b.

5 For a discussion of time as a structuring device in Forward, see Balestrini 2019b.

6 Sterne 2012, 2.

7 Sterne 2013, 183.

8 Paying attention to the many facets and implications of sound in the theatre also complements the comparatively recent trend in the natural sciences which are - slowly but surely - becoming attuned to sound as an epistemological resource on a par with the visual (Pinch and Bijsterveld 2012, 11-12). 
climate change in each play. The plays address and/or depict prerequisites of sound production, the affective impact of sounds, and specific listening practices. Emphasizing sound foregrounds cultural values linked to indigeneity, white settler colonialism, and specific senses of entitlement based on gender, class, and human privilege. In the first two plays of the Arctic Cycle, sonic features reveal competing methods of individual characters' meaning construction and self-assertion, all of which are contextualized within an understanding of anthropogenic climate change and its interrelations with settler colonialism and capitalist profit-seeking. The evolving series of plays ultimately contributes to developing innovative aesthetics keen to express a decolonial sense of planetary interconnectedness.

\section{Sila: The Breath of Life}

As Bilodeau explains: "In Inuit cosmology, [sila is] the primary component of everything that exists". ${ }^{9}$ Various characters in the play define sila as the basic element in community building, as "breath" and air "all around us", and as the necessary energy to transform "will" into "words". ${ }^{10}$ Consequently, Sila addresses the fact that access to and control of breath are central prerequisites for making one's vocal powers audible, and that doing so is a matter of life and death. This existential theme permeates spoken words in Inuktitut, French, and English in the play, which comprises verbal utterings of humans, of a polar bear mother and her female cub, and of mythical creatures of the Arctic Sea as well as recurring and interlinked non-verbal sounds like breathing, throat-singing, the wind, and ice breaking. These varieties of sounds and languages indicate the co-presence of cultural difference and of the possibility of communication, empathy, and collaboration across boundaries of cultures and even of species, if only the various creatures are willing to listen to one another.

Overall, the play's use of sound indicates that what we hear is neither noise nor purely individual self-expression, but that it frequently involves communication with others for the sake of survival. In one of the subplots, a Canadian Coast Guard dispatcher keeps talking to the struggling crew of a sinking ship in order to convey hope (II,vi and II,ix), but all rescue efforts fail. More central to the play, the spoken-word poet Veronica temporarily loses her ability to speak when her teenage son dies of sniffing gasoline (II,viii); eventually, empathy enables her to shed tears and regain sila (II,xiii) after Jean, a French Canadian researcher, shares his grief about his still-born child (II,xi). In these instances, interpersonal communication goes beyond exchanging words. Rather, Veronica's emotional release occurs exactly when the deceased polar bear cub's spirit ascends to the metaphysical realm; both experiences imply the freeing of the soul of Veronica's son, whose death is echoed in the polar bear cub's death. The recurring references to life-giving sila and thus to an Inuit concept which applies to everyone in the play's fictional world offers an alternative to Western universalist thinking.

Although sila is depicted as potentially connecting previously separated or

9 Bilodeau 2015, 9.

10 lbid., 43 and 71. 
unconnected beings and worlds, the tension between Inuit-related sounds and sounds produced by whites remains. While the playwright perceives it as one area in which contrasting understandings of the Arctic become perceivable, the use of sound in the play aims at overcoming this contrast to some extent. In her "Playwright's Notes" to Sila, Bilodeau writes that "There are two distinct Arctics in this play: the Arctic of the Inuit and the Arctic of the Southerners [i.e., non-Inuit Canadians living South of the Arctic]. The Arctic of the Inuit is warm, raw, and fiercely alive. It feels and sounds like the music of Tanya Tagaq". ${ }^{11}$ Bilodeau's emphasis on the Inuit conception of the Arctic as representing a kind of sheer life force goes against Western clichés about cold climates being static, immobile, possibly frozen to death or at least frozen in some unfathomable past.

Although the stage directions of Sila suggest rather than demand the use of specific music, Bilodeau's recommendations indicate that musical sound serves as a stand-in for specific cultural concepts. For instance, the play's prologue shows the Inuit elder Tulugaq "sculpting a piece of soapstone. The wind morphs into a sort of breathing" which eventually "turns into Inuit throat singing. (Possibly "Force" by Tanya Tagaq.) It is intense, contemporary, unnerving". ${ }^{12}$ This is not folk music meant to please the ostensibly open-minded Western ear, but it is emotionally gripping and modern. Similar to the prologue, the suggested sonic underpinnings of the play's turning point, which presents Veronica's climactic moment of liberation and empowerment, reinforces the allencompassing presence of sila through Tanya Tagaq's "Sila", a song in which Tagaq experiments with features of Inuit throat singing. ${ }^{13}$ Significantly, Tagaq's use of throat singing counteracts nostalgic and potentially essentializing listening practices associated with the so-called 'world music' segment of the recording industry. ${ }^{14}$ Her song "Sila" not only demonstrates the compatibility of traditional indigenous musical techniques with twenty-first-century popular music aesthetics; it also reinforces Inuit cultural independence, particularly in light of the fact that throat singing had been prohibited by church authorities until the 1980s. Its revitalization, be it in its traditional practice or in adapted forms like Tagaq's, participates in Inuit reclaiming their land and culture. ${ }^{15}$

In contrast to Tagaq's decolonizing gesture, Bilodeau characterizes white Canadians' perspective as follows: "The Arctic of the Southerners is cold, mystical in its foreignness, and rarefied. It feels and sounds like John Luther Adams's album The Far Country [1993]". ${ }^{16}$ Mississippi-born John Luther Adams lived in Alaska for forty years and has released multiple prize-winning albums

11 Ibid., 5.

12 Ibid.

13 Ibid., 99. A recording of Tagaq's "Sila" is available at <https://www.youtube.com/ watch?v=w3TpDQ0vsB4>. Bilodeau prepares this link between breath, survival, poetry, and throat singing through the performance of Veronica's spoken-word poem "Eskimo Chick" (I,vi, 24-25) in which "the guttural sound 'ahhma' is similar to Inuit throat singing" ("Playwright's Notes," Bilodeau 2015, 5).

14 Keogh 2019; Stévance 2017, 48.

15 Richardson 2014; Robinson 2012, 240-1, 246.

16 Bilodeau 2015, 5. 
that take Alaskan landscapes as their inspiration for what he calls "sonic geography,' a music of place". ${ }^{17}$ Apparently, the playwright does not connect with the classically trained composer's work, which sometimes relies on traditional orchestra instruments and at other times employs computer-generated sounds. ${ }^{18}$ Adams, however, would probably not welcome such a clear-cut juxtaposition between indigenous and non-indigenous sonic arts, as he has spent decades contemplating non-appropriative ways of bringing together different cultural traditions. ${ }^{19}$ Be that as it may, the proposed dichotomy certainly highlights the fact that, to Bilodeau, sonic features in climate change drama can contribute crucially to the representation of cultural hierarchies or heterarchies.

The challenge of staging plays with culturally diverse music and other sounds resembles the dilemma involved in contemporary compositions and performances that bring together indigenous and Western music in Canada. Dylan Robinson, who has studied such practices, discerns three models, all of which raise difficult questions regarding "the sonic positionality of encounter" ${ }^{20}$ Rather than setting out to solve these problems in Sila, Bilodeau opts for suggesting the works of Tanya Tagaq because they demonstrate that Inuit music traditions are alive and malleable, and that they are not simply stuck in the stereotypical rut of unchanging stability which Western culture may both look down on and desire. In contrast, Forward features the elaborate use of specific musical numbers that signify time, cultural belonging, and struggles for survival and leadership. These struggles comprise small-scale social relations (as in a family) and large-scale attitudes towards the nation or specific geographical spaces, including their resources.

\section{Songs of Appropriation and Defiance in Forward}

While the central plot of Forward pivots around Fridtjof Nansen (1861-1930), the play's time frame extends from 1893 to the year 2013. The title refers to the polar explorer's ship, Fram (Norwegian for "forward"). In addition to the extensive temporal reach, the play juxtaposes and intersects multiple realities. First, 'real-world' settings include multiple locations in Norway as well as the route that Nansen and his crew took in their attempt to reach the North Pole. Second, the stage directions in some scenes specify a reality beyond human conceptualizations and perceptions: the character named Ice lives "in her own reality outside of time". ${ }^{21}$ This stipulation undermines the idea that human time suffices as a framework for non-human contexts. Ice thinks and feels in dimensions that evoke geological ages like the Anthropocene (which is a debatable, controversial human construct). Moreover, Ice never speaks; instead,

17 Young 1998. Strangely enough, Adams wrote a composition that shares its title with Bilodeau's play: Sila: The Breath of the World. This work premiered on 25 July 2014, that is, three years after Bilodeau's Sila had won first prize in the Uprising National Playwriting Competition (2011), two years after winning first prize at the Earth Matters on Stage Ecodrama Festival (2012), and in the year of the play's first full production in New Hampshire (2014).

18 For details, see johnlutheradams.net.

19 He describes this in detail in Adams 2009.

20 Robinson 2012, 229; also see 235, 237.

21 Bilodeau 2017, 4. 
she performs more songs than any other character in the play. Restricting her vocal expression to singing further emphasizes her separateness from the human realm.

Bilodeau stresses the importance of the songs in Forward by requiring the individuals who embody Nansen, his first wife, Eva, and Ice to be "singers" who possess classically trained voices. ${ }^{22}$ In contrast, members of the crew on Nansen's ship, i.e., seafarers who sing a shanty-like song that produces an atmospheric local-colour effect and underscores their physical work, are played by singing actors. Their work song emphasizes traditional cooperative labour aboard a ship_labour that is meant to keep everyone safe while they are on the move. ${ }^{23}$ In contrast to the crew members' on-board singing, Nansen listens to recordings of nineteenth-century art music performed by his first wife, Eva Nansen, who was a professional singer. In the course of the play, she performs an aria from an opera by Héctor Berlioz in French and two songs by Franz Schubert in German. The language barrier created by the lyrics (both for Nansen's Norwegian-speaking crew and possibly for English-speaking audiences) immediately taps into centuries-old debates about how performing operas in foreign languages is a white European middle- and upper-class practice meant to exclude less educated individuals. In addition to Nansen's 'elevated' musical taste, the habit of listening to such music in the Arctic with the help of 'cutting-edge' technology (the phonograph was invented in 1877, i.e., less than twenty years before his exploratory journey) bespeaks his social standing. Furthermore, the lyrics of the aria and the songs address existential matters such as the close link between sexual attraction and death, and perseverance in achieving one's personal aspirations even if others have to pay a price for that.

While the play contrasts amateur and professional singers whose singing abilities also imply class differences and a power differential, as is the case with the ship's crew as opposed to Nansen as their leader, Bilodeau otherwise avoids clear social dichotomies linked to the choice of musical styles that the singer-performers present or listen to. Sonic differences can potentially indicate different or clashing emotional worlds, but two characters that sing in a similar style and even in a duet-like song do not necessarily inhabit the same time, space, and reality. Furthermore, specific musical styles are not simply tethered to the time of their genesis and of their popularity in a specific context. Rather, music in the play transcends time-bound divisions and establishes linkages between Nansen's lifetime, the twenty-first century, and geological time spans. As a result, the lyrics play a crucial bridging function between the musical numbers and between the songs and the spoken words of the play. Both the nineteenth-century classical music by Berlioz and Schubert and the contemporary music written by Aggie Peterson (b. 1975), an electro-pop artist from Troms $\varnothing$ who has been a member of Frost since 1998, feature words on existential themes such as love and death, desire and survival.

Electro-pop performed by groups like Frost combines synthesizers and

22 Ibid., 5.

23 Ibid., 9-10, 73. 
electronic drum machines with narrative ballads or introspective emotional lyrics. Peterson's compositions do not require classical vocal training to master the tonal language, melodies, vocal range, and rhythmic structures. The relation between verbal syllables and musical pitches does not permit drawing out vowels as in much operatic music; instead, the songs sound rather conversational. As Bilodeau wants the singing not to assume the melancholic characteristics of Peterson's own style but rather to be "forceful and dynamic" 24 through the level of the singers' training, the voice quality and vocal method, instead of the compositional style, are meant to emphasize especially lce's assertive and perilous characteristics.

From the perspective of Eva Nansen in the play, the North Pole metonymically personified in Ice - is her main competitor when it comes to her husband's affection. Although this love triangle incorporates a conventional operatic juxtaposition of female voices (Eva Nansen's soprano vs. Ice's alto), the lyrics transcend a simplistic antagonism. In traditional Western opera, this particular sonic difference frequently serves the following constellation of stock characters: the soprano represents a positively connoted, even haplessly innocent victim, whereas the alto plays the role of a morally unsound, dangerous, and even violent perpetrator, or at least a more agentic and thus less submissively feminine character. Torn between these two female figures, Nansen's infatuation with exploration and with its concomitant physical danger comes across in the musical numbers' lyrics which rhapsodize the close link between passion and death (i.e., an eros-and-thanatos motif); at the same time, the musical numbers critique the narrative of gender hierarchy and female submissiveness in nineteenth-century European middle-class thought. Breaking through the nineteenth-century framework, the way Bilodeau integrates the songs into scenes shows how the three central characters' internal struggles have resurfaced in the ways in which post-Nansen generations have tried to make sense of Arctic exploration, oil drilling, upward social mobility, and climate change. Nansen seems tragically stuck between Eva and Ice, and between enjoying Eva's recordings and bristling at Ice's seemingly face-to-face singing (which Nansen cannot hear, but only somehow sense, whereas the audience members see and hear Ice). Later generations in the play, like Nansen before them, can only discern the nineteenth-century classical works. The sonic worlds of Ice's and Nansen's singing thus only exist on the meta-level of performance, which allows the two characters' voices to mingle in the audience's ears, even though they remain physically separate in the fictional world of the play.

\section{Songs of Love and Death}

Multiple songs characterize Ice as a dangerous (and anything but docile or weakly feminine) force that will overwhelm and potentially destroy Nansen. "Millennia" (scene 1) introduces Ice as "magnetic and fierce / enticing and dangerous" 25 to the extent that she claims: "You are mine to take, mine to

24 Email from Chantal Bilodeau to the author of this essay (15 January 2018).

25 Bilodeau 2017, 10. 
possess / Mine to cherish and to bless". ${ }^{26}$ The songs "Just So"27 and "Fierceness of My Love" also express the closeness of raw passion and physical violence. ${ }^{28}$ Struck by his desire to conquer the Arctic, Nansen literally 'falls for her' after she triumphantly prophecies that, while she "dare[s] [him] to prove" that he can "grab and handle" her, she will "turn [him] black and blue". ${ }^{29}$ As the audience realizes, Nansen's life is on the line at this point because he has thrown himself onto the ice and now needs to be revived (scene 13).

Just as songs link the separate worlds of Ice and Nansen, at least in the audience's perception, a split-screen or, rather, a split-stage technique unites live performance and the experience of listening. In Scene 10, Eva Nansen performs Schubert's "Gretchen am Spinnrade" ("Gretchen at the Spinning Wheel") in Norway, while her husband and his ship's captain enjoy a recording of her voice on the Fram. Analogous to Nansen's above-described inability to resist Ice, Gretchen's sense of helpless longing for Faust stresses the mythical quality of extreme desire. Connectedness through sound cuts across geographical distance as much as it projects the emotional impact of tragic love relationships from the dramatic and lyrical renderings of the Faust legend onto Nansen's life story and the long-term impact of Arctic exploration.

As indicated, Nansen and Ice neither touch physically, nor hear each other's voices. In the theatre, of course, the presence of both characters on one stage and the mingling of the sounds they produce imply their reciprocal impact. In addition to the scenic effect, the lyrics verbalize the paradoxical push and pull of attraction and repulsion, and the dilemma of oneness and separateness. An example of this is a 'duet' (in scene 16) sung by "ICE and NANSEN in their separate realities" ${ }^{30}$ which raises rather than answers questions regarding future survival or disaster. Similarly, in scene 22, Ice verbally appreciates Nansen's dedication to the Arctic; yet, her appreciation again invites him to let his passion culminate in a kind of Wagnerian Liebestod: "Come rest in my arms // For me / Lay down your life". ${ }^{31}$ As if in response, Ice's song partially overlaps with a monologue in which Nansen pleads, seemingly with her, to take him to the pole so that he can prove the value of exploration. When - in the following, final scene - Nansen returns to Norway, Norwegians waiting for his ship's arrival disagree regarding his merits. Nansen's pronouncements then echo Ice's words when he expresses his fascination with her ${ }^{32}$ and his conviction that "the ice is as demanding as she is giving / And though I am certain / she holds the key to our future / beware the man who subdues her / for the cost will be greater / than anything we could ever imagine". ${ }^{33}$ Fittingly, Ice gets the last word by singing her final song and remaining on stage by herself. Her lyrics confirm the paradoxical separateness and inseparableness of the Arctic and human explorers

26 Ibid.

27 This song is split into two parts, opening scene 3 (op. cit., 20-21) and closing scene 6 (37).

28 Ibid., 54.

29 lbid.

30 lbid., 74.

31 Ibid., 103.

32 Ibid., 109

33 Ibid., 110. 
("Together but alone"). The onus of destructive perseverance, nevertheless, lies with humans who "Backward or forward / [. . .] go on in foolish bliss". ${ }^{34}$ Ultimately, Ice's sonic presence establishes her as a natural force that asserts her domination over foolish men. Although the lyrics attribute anthropomorphic features like a psychology of desire and of power relations to her, and although Ice is seen and heard on stage alongside human characters, the dividing line between her realm and the human world remains drawn throughout the play.

In addition to overcoming spatial distance, vocal music also supports the temporal structure of Forward through strategic placement of songs within scenes and through thematic intersections between Aggie Peterson's lyrics and the poetry set to music two centuries before. Scene 10 begins with Schubert's "Gretchen" song and ends with one of Peterson's compositions. Even more structurally effective, scene 18 reinforces the earlier comparison between Eva Nansen and lce in a manner that reverses the nineteenth-century cliché of male seducer and female victim by emphasizing Ice's ability to overpower Nansen. Focused on Nansen's funeral in 1930, said scene features Eva Nansen singing Schubert's "Der Tod und das Mädchen" ("Death and the Maiden"). Curiously, one might think that a sonic reference to the explorer's first wife, who died in 1907, might primarily serve as a reminder of how difficult he made her life by staying away from his family for years and by being a womanizer. Eva's vocal presence may, nonetheless, also imply a reversal in the gender-based power differential because, earlier on, Nansen succumbed to Ice's seductiveness and because the motif of death as a lover occurs in Eva's performance as well as in Ice's song: the lines in which Ice invokes Nansen's death ("Come rest in my arms // For me / Lay down your life" ${ }^{35}$ ) closely resemble Matthias Claudius's verse in Schubert's song: "Sollst sanft in meinen Armen schlafen" 36 ("you shall sleep comfortably in my arms"). Eva's death song thus refers to Nansen succumbing to deadly passion rather than to her own demise.

\section{A Faustian Pact versus Posterity}

In addition to intersecting the comparatively short time span of Nansen's first marriage and the immense time span of Arctic Ice's existence, the music in Forward links the conflict in Nansen's family story with the long-term impact of polar exploration and the fossil fuel industry on Norwegians to the present day. Several scenes thus depict the effects of individual passions and/or decisions on parent-child relationships in light of the exploitation of natural resources.

Prepared by the musical representation of Nansen's competing love interests - Eva and Ice - the above-described funeral scene (scene 10) closes with Liv Nansen wondering whether her father really loved her or whether he valued Arctic exploration more. These musings serve as a transition to scene 11, which is set partially in 1894 and in 1972. In the twentieth-century setting, a father pours out his heart to his baby daughter in her crib. He explains that he, as the breadwinner, must leave his family for long stretches of time to work on an oil

34 Ibid., 111.

35 Ibid., 103.

36 Ibid., 81. 
rig in order to improve the socioeconomic circumstances of future generations; his dream of a better life shows no awareness of climate change.

Significantly, like Nansen, the father associates going to the opera with upward mobility, imagining that financial success will allow him to afford a live performance of "D'amour l'ardente flamme" from Berlioz's La Damnation de Faust. Cutting to 1894, we see Nansen's wife perform the piece, after which said father imagines Norway's economic success, his daughter's university education, and her well-paid job. When the baby begins to cry, Eva Nansen from the past approaches the crib, saying, "Pappa is not worth crying for" - as the twentieth-century father hurriedly exits with the promise, "I will be back soon". ${ }^{37}$ In contrast to Faustian Nansen, this husband/father experiences pressure from outside forces to conform to social expectations as a male provider. Like Nansen, he shows no ability to imagine the environmentally detrimental effects of his ostensibly lucrative work.

Nineteenth-century classical singing does not simply provide respite from emotionally uncomfortable and politically fraught current topics like climate change, environmental destruction, and gender inequality. Embedding Berlioz's aria within this scene rather illustrates the timelessness of conflicts between socially prescribed, gendered, and class-based personal goals, be it in the lives of famous individuals or of nondescript individuals whose class-standing erased them from historiography. The sonically reinforced motif of the Faustian pact thus applies to myriad acts of evaluation and prioritization of moral and ethical convictions.

Bilodeau's heterarchical aesthetic in Forward mostly surfaces in the simultaneous onstage presence of different moments in the play's extended temporal range. While ethnicity is central to social hierarchies in Sila, the second Arctic Cycle play rather thematizes gender and class as markers of a power differential. In both works, the inclusion of non-human characters offers pathways into rethinking various traditional practices of privilege and their detrimental impact on the less privileged and unprotected.

\section{Planetary Relationality in Thought and Practice}

How, then, do the sonic features of Bilodeau's first two Arctic Cycle plays contribute to representing Arctic environments, Inuit culture, and white Western cultures as part of understanding climate change? As indicated at the beginning of this article, theatre practitioners - such as those associated with CCTA - have been engaging in heated debates about how to avoid Eurocentric conventions, especially when representing indigenous Arctic cultural practices. In her approach to developing plays, Bilodeau has been keen on researchbased critical thinking in pursuing an at least partially new aesthetic. While her plays are still anchored in Western theatrical traditions, despite efforts to adapt them to the demands of climate change drama, she has sought to uncover and critique colonial hierarchies in the past and the present. ${ }^{38}$

As discussed, Sila relies less on music than on the implications of wind, breath,

37 Ibid., 58.

38 See Balestrini 2020, 40, 45. 
and the absence or presence of spoken language (presented as poetry, oratory, and multilingual dialogue). Some sounds mentioned in the stage directions simply provide scene-specific sonic contexts, such as "the sound of bubbles rising to the surface followed by a tinkle of water" $(\mathrm{I}, \mathrm{V}, 19)$ when the two polar bears are unsuccessfully hunting for seals, or "[t]he sound of a snowmobile" $(\mathrm{I}, \mathrm{X}, 44)$ and two gunshots $(\mathrm{I}, \mathrm{x}, 44-5)$ following upon the "[f]riendly growling and laughter" $(I, x, 41)$ of the said polar bears, thus prefiguring their deaths. More importantly, the variations on breath and wind range from moments of existential threat to joining in with the universe's rhythm. Thus, audiences will hear the painful "panting" (I,xv,59; also see II,iv,71) of the exhausted polar bears, the non-verbal wailing of the mythical sea creatures that Jean perceives after breaking through Arctic ice ("Muffled voices create a tapestry of plaintive sounds" [II,vii,81]), and multiple cries of pain or suffering (I,Xv,61; II,v,75; II,vii,85; II,vii,87). At the other end of the spectrum, the polar bear cub's transition from earthly life to metaphysical life is made audible through synchronizing the dying animal's rhythmic breathing with that of "the Earth" $(I, x v, 60){ }^{39}$

Bilodeau's above-quoted juxtaposition of two sonically and conceptually distinct Arctics - those of the Inuit and of white Canadian Southerners, of Tanya Tagaq and John Luther Adams - might raise eyebrows regarding the danger of establishing essentialist binaries. Yet, as the stage directions only suggest but do not prescribe the use of Tagaq's music, and as they do not suggest playing Adams's music anywhere in the play, the playwright may merely be wishing to point out a range that directors can draw on. As Robinson argues, combining indigenous Canadian and Western compositions, be it within a single work or as part of a concert program, may foster grand national myths about intercultural harmony which can co-opt indigenous cultures by romanticizing their supposed integration within national culture, subsuming them without granting them an independent voice. ${ }^{40}$ Sila clearly avoids this pitfall by foregrounding the Inuit concept of sila and by making it audible through the sounds of the wind, breathing, and the option of including a popular music-inflected form of throatsinging. The focus on breath as the prerequisite of life and of verbal selfexpression (and thus meaning-making) rather than on music precludes, to use Robinson's phrase, an "aesthetics of pastiche" sometimes found in non-verbal sonic art works that can potentially instrumentalize indigenous art. Instead, the play engages in "a reciprocal presentation of cultural traditions and repeated encounters" that strives towards "bi-directional" communication, as the dialogue on stage and the use of spoken-word poems by Inuit poet Taqralik Partridge confirm. ${ }^{41}$

If a production of Sila were to include Tagaq's recordings, the performance could use her art to support how the play depicts twenty-first-century Inuit as keenly aware of current issues and well-versed in indigenous and white Canadian cultures and politics. Similarly, Stévance finds that Tagaq's re-

39 Interestingly, Veronica's inability to form words is conveyed not simply through silence but also through projecting jumbled letters that represent her failed attempts at using language (II,iii,68).

40 Robinson 2012, 226-7, 232-3, 237.

41 Robinson 2012, 245-6; Bilodeau 2015, 5. 
casting of throat singing in an electro-pop matrix stresses her agency as an artist "rooted in two cultures". ${ }^{42}$ Indeed, Stévance interprets Tagaq's work as expressing "the emergence of a new cosmopolitanism". ${ }^{43}$ From an American Studies perspective, I nevertheless advise caution regarding Stévance's use of the terms 'modernity' and 'cosmopolitanism' without providing any context. As Walter D. Mignolo and Catherine E. Walsh argue, studying "decoloniality" requires "awareness of the integral relation and interdependence amongst all living organisms (in which humans are only a part)"; they also suggest that the close relation between "modernist" and "coloniality" evokes Eurocentric claims to the "universal" which should be replaced by a "pluriversal" perspective which envisions Western thought as one among many outlooks. ${ }^{44}$ What makes this approach doubly attractive for discussing Bilodeau's research-based aesthetics is Walsh and Mignolo's emphasis on "theory and praxis". ${ }^{45}$

In Forward, the use of technologically advanced electropop and nineteenthcentury classical singing similarly fosters the notion that the Arctic is not tethered to potentially vanishing cultural modes of expression but requires a constructive future-oriented response. The intricate temporal structure of Forward, strengthened by the multiple links among the musical numbers, vividly argues in favour of considering long-term human activities when assessing the Arctic's condition. Thus, the nineteenth century Kunstlieder serve as reminders of ingrained features in human predicaments, such as prescriptive gender roles, intense passions, and the disastrous consequences of hubris.

As Bilodeau conceptualized the Arctic Cycle as a series of plays about an interconnected geographical area and the global phenomenon of climate change, my central question has been whether and how the playwright uses sonic features to interconnect two plays set in two different regions and featuring unconnected casts of characters and plots. As I have shown, Sila and Forward feature multilinguality and music. Both are concerned with Arctic ice and its destruction through climate change. In fact, the thematically given focus on ice plays an important role in both plays not just in terms of the central conflicts but also because in both plays Arctic ice is rendered audible. ${ }^{46}$ Forward does not only refer to the sound of ice enclosing Nansen's ship ${ }^{47}$ but also allegorizes Ice in the shape of a human singer. In Sila, we hear the sounds of "cracking sea ice" 48 , and the verbal narrative of mythical sea creatures leads up to the turning point in the above-mentioned French-Canadian scientist Jean's attitude towards the Arctic: while waiting to witness the imminent detachment of large ice sheets, ${ }^{49}$ Jean breaks through the ice and falls into the sea. ${ }^{50}$ In the subsequent surreal

42 Stévance 50; also see 54.

43 Ibid. 56.

44 Walsh and Mignolo 2018, 1, 3.

45 Ibid. 7, also see 9.

46 E.g., Bilodeau 2015, 17. On art projects involving the sights and sounds of disintegrating Arctic ice, see Dumitriu, Tenetz, and Lawrence 2010, 486.

47 Bilodeau 2017, 22, 23.

48 Bilodeau 2015, 53.

49 Bilodeau 2015, 13.

50 Ibid., 75. 
scene, he is shown as being literally immersed in an Inuit account of the Arctic's condition (II,vii), an experience that prepares him to perceive the Arctic not only through scientific measurements but also as a complex historical and cultural cross-species phenomenon. He, then, also triggers the bereaved Inuit mother Veronica's process of openly mourning her son's death and of regaining her sila and, thus, her voice. Both plays artistically mediate specific understandings of the Arctic in order to raise awareness of what Hester Blum poignantly describes as an "archive of human toil and tragedy" alongside "nonhuman processes of accumulated and diminishing ice". ${ }^{51}$

Furthermore, the evolving aesthetics of Bilodeau's Arctic Cycle achieve what Amy Elias and Christian Moraru associate with a "planetary" perspective which "reaches beyond the hermeneutical to the ontological" 52 , that is, from foregrounding interpretation to fathoming uncharted depths of being. As the principle of all things being interrelated is an all-pervasive element of planetary being, "planetarity opens itself [. . .] to the nonhuman, the organic, and the inorganic" - as is the case in Bilodeau's plays. ${ }^{53}$ And this is why the arts and particularly theatre can play a pivotal role in communicating climate change: artistic works can strive to communicate "a complex planetary network" whose internal workings are "bioconnective" because they clarify "the connection of bodies in space and time", forcing us to "read[. . .] comparatively" across cultures, and because they engage in "worlding the world, making it a world of relations, and attending to them".$^{54}$ Similarly, the Arctic Cycle plays both point out relations and explore these relations in depth without suggesting prescriptive, homogeneous structures. In this sense, studying serial climate change drama contributes to current research on decolonial planetary perspectives.

51 Blum 2016.

52 Elias and Moraru 2015, xxiii.

53 Ibid., xxviii. Regarding relationality as a central concept, also see Walsh and Mignolo 2018, 1.

54 Elias and Moraru 2015, xxiv. 


\section{AUTHOR}

Nassim W. Balestrini is Professor of American Studies and Intermediality at the University of Graz, Austria, and Director of the Centre for Intermediality Studies in Graz (CIMIG). Before moving to Austria, she taught at the universities of Mainz, Paderborn, and Regensburg in Germany and at the University of California, Davis. Her research interests include American literature and culture, adaptation and intermedial relations, life writing across media, hip-hop culture, climate change drama, US-American and Canadian theater and performance, African American literature and culture, and the poet laureate traditions in the United States and in Canada.

\section{REFERENCES}

Adams, John Luther. 2009. The Place Where You Go to Listen: In Search of an Ecology of Music. Middletown, CT: Wesleyan UP.

----- 1988. "Sonic Geography of the Arctic." Musicworks 70 (Spring). Reissued at: http:// johnlutheradams.net/sonic-geography-of-the-arctic-interview/ (28.3.2019).

Balestrini, Nassim Winnie. 2020. “. . . writing plays that are climate change': An Interview with Chantal Bilodeau." In Nassim W. Balestrini, Leopold Lippert, and Maria Löschnigg (eds.). Special Issue on "Theater of Crisis: Contemporary Aesthetic Responses to a Cross-Sectional Condition". Journal of Contemporary Drama in English 8:1.

----- 2019a. "Transnational and Postcolonial Perspectives on Communicating Climate Change through Theater." In Walter Leal Filho, Bettina Lackner, and H. McGhie (eds.). Addressing the Challenges in Communicating Climate Change Across Various Audiences. Berlin: Springer, 247-61.

----. 2019b. "Climate Change Drama across Time and Space: Chantal Bilodeau's Forward (2016)." In Maria Löschnigg and Melanie Braunecker (eds.). Green Matters: Ecocultural Functions of Literature. Leiden: Brill, 295-307.

2017a. "Cli-Fi Drama and Performance." In Susanne Leikam and Julia Leyda (eds.).

"'What's in a Name?': Cli-Fi and American Studies (Extended Forum)." Amerikastudien/ American Studies 62:1, 114-20.

----. 2017b. "Climate Change Theater and Cultural Mobility in the Arctic: Chantal Bilodeau's Sila (2014)." In Kerstin Schmidt and Nathalie Aghoro (eds.). Special Issue on "Theatre and Mobility". Journal of Contemporary Drama in English 5:1, 70-85. DOI: https://doi.org/10.1515/ jcde-2017-0006.

Bilodeau, Chantal. 2017. Forward. Vancouver: Talonbooks.

2015. Sila. Vancouver: Talonbooks. 
Blum, Hester. 2016. "Speaking Substances: Ice." Los Angeles Review of Books 21 March 2016, https://lareviewofbooks.org (20.9.2018).

Dumitriu, Anna, Antti Tenetz, and Dave Lawrence. 2010. "KryoLab." Leonardo 43:5, 486-87. J- STOR (13.3.2019).

Elias, Amy J., and Christian Moraru. 2015. "Introduction: The Planetary Condition." In Amy J. Elias and Christian Moraru (eds.). The Planetary Turn: Relationality and Geoaesthetics in the Twenty-First Century. Evanston: Northwestern UP, xi-xxxvii.

Keogh, Tom. 2019. "Tanya Tagaq Takes Inuit Throat Singing to Wildly Unexpected Places." Seattle Times 30 January. https://www.seattletimes.com/entertainment/music/tanya-tagaqtakes-inuit-throat-singing-to-wildly-unexpected-places/ (13.3.2019).

Pinch, Trevor, and Karin Bijsterveld. 2012. "New Keys to the World of Sound." In Trevor Pinch and Karin Bijsterveld (eds.). The Oxford Handbook of Sound Studies. Oxford: Oxford UP, 3-35.

Richardson, Jennifer. 2014. "Inuit Throat-Singing: A Guttural Game Gets a Cultural Resurgence." Atlas Obscura 30 January. https://www.atlasobscura.com/articles/throat-singing-from-canadas-inuit (13.3.2019).

Robinson, Dylan. 2012. https://pure.royalholloway.ac.uk/portal/en/publications/listening-to-thepolitics-of-aesthetics-contemporary-encounters-between-first-nationsinuit-and-early-musictraditions(d64b6b5d-3f92-4903-8b79-e9020ff72277).html In Anna Hoefnagels and Beverley Diamond (eds.). Aboriginal Music in Contemporary Canada: Echoes and Exchanges. Montreal: McGill-Queen's UP, 222-48.

Sterne, Jonathan. 2013. "Soundscape, Landscape, Escape." In Karin Bijsterveld (ed.). Soundscapes of the Urban Past: Staged Sound as Mediated Cultural Heritage. Bielefeld: Transcript, 181-93.

----- 2012. "Sonic Imaginations." In Jonathan Sterne (ed.). The Sound Studies Reader. New York: Routledge, 1-18.

Stévance, Sophie. 2017. "From Throat Singing to Transcultural Expression: Tanya Tagaq's Katajjaq Musical Signature." In Stan Hawkins (ed.). The Routledge Research Companion to Popular Music and Gender. Abingdon and New York: Routledge, 48-62. 